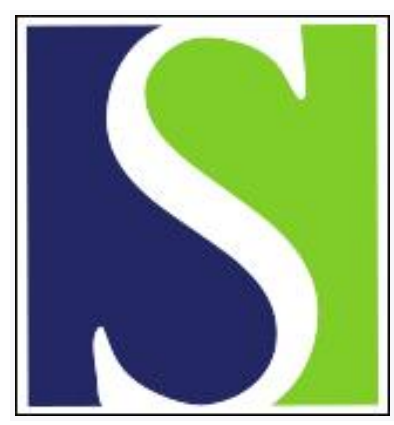

Scand J Work Environ Health 1982;8(1):63-69

https://doi.org/10.5271/sjweh.2495

Issue date: Mar 1982

Application of the chicken embryo in testing for embryotoxicity: thiurams.

by Korhonen A, Hemminki K, Vainio H

Key terms: arterial blood; body fat; chicken embryo; embryotoxicity; exercise; human; needle biopsy; rest; testing; thiuram; uptake

This article in PubMed: www.ncbi.nlm.nih.gov/pubmed/7134924

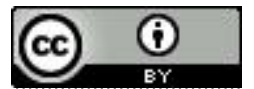




\title{
Application of the chicken embryo in testing for embryotoxicity
}

\section{Thiurams}

\author{
by Aila Korhonen, Kari Hemminki, MD, Harri Vainio, MD ${ }^{1}$
}

\begin{abstract}
KORHONEN A, HEMMINKI K, VAINIO H. Application of the chicken embryo in testing for embryotoxicity: Thiurams. Scand $j$ work environ health 8 (1982) 63-69. A test protocol was developed for the testing of chemicals for toxicity on the chicken embryo. The protocol called for a continuous monitoring of the developing embryo for those that died before maceration. The eggs were injected on day 3 , and the test was continued up to day 14 of incubation. The following parameters of embryotoxicity were used: early deaths (spanning the first $2 \mathrm{~d}$ after injection), late deaths with malformed embryos, Iate deaths with nonmalformed embryos, and malformed survivors. The order of embryotoxic potency, in descending order, among the thiurams was tetramethylthiuramdisulfide, tetramethylthiurammonosulfide, tetraethylthiuramdisulfide. It was found that late deaths were seen in $70 \%$ of the cases with malformations. The most common types of malformations were eye defects and open coeloms. Dead embryos frequently had multiple malformations. In lethal cases, embryonic development terminated at stages $25 / 26$ and 29 on the Hamburger-Hamilton scale.
\end{abstract}

Key words: embryonic deaths, malformations, teratogenicity, tetraethylthiuramdisulfide, tetramethylthiuramdisulfide, tetramethylthiurammonosulfide.

The parameters used to measure teratogenicity and other embryotoxic effects vary, depending on the method and on the scientist. Loosely defined terms, such as "high" or "low" doses are used even in the recommendations of the World Health Organization, as noted by Jelinek \& Rychter (3). This problem stems, to a great extent, from a nonuniform application of the parameters to measure effects and, in some systems, even on the lack of such parameters. Most of the parameters are based on a dose producing a certain effect, and generally this effect is calculated in relation to the number of survivors. As increasing concentrations of a test chemical always involve embryonic deaths, the number of malformed survivors may not accurately reflect the

1 Department of Industrial Hygiene, Institute of Occupational Health, Helsinki, Finland.

Reprint requests to: $\mathrm{Dr} \mathrm{H}$ Vainio, Institute of Occupational Health, Haartmaninkatu 1, SF-00290 Helsinki 29, Finland. teratogenic potential of the chemical.

In this study a method utilizing chicken embryos is employed to allow observation of each exposed embryo throughout the whole period of embryonic development. The advantage of continuous observation is that dead embryos can be readily recorded and inspected before maceration. This procedure facilitates a precise definition of the different embryotoxic effects.

Three thiuram compounds, tetramethylthiuramdisulfide (TMTD, thiram), tetramethylthiurammonosulfide (TMTM) and tetraethylthiuramdisulfide (TETD, disulfiram, Antabus), were selected as the test substances. TMTD has been found to be a teratogen in mice (5) and hamsters (4). TETD has also caused malformations in hamsters but only when introduced in dimethylsulfoxide (4). All three of the thiurams tested are extensively used in rubber as curing agents and accelerators. TMTD is additionally widely used as a pesticide, and TETD as a drug in the treatment of alcoholism. 


\section{Materials and methods}

White Leghorn chicken eggs were obtained from the hatchery of Siipikarjanhoitajain Liitto ry, Hämeenlinna, Finland. The incubator was commercially manufactured by Hämeen Insinööritoimisto $\mathrm{Oy}$, Hämeenlinna.

TMTD and TMTM were obtained from the rubber factory of Nokia, Finland, and were of technical grade; TETD, pro analysis grade, was purchased from the Sigma Chemical Company, St Louis, MO, USA. Acetone, pro analysis grade of Merck, Darmstadt, Federal Republic of Germany, was used as the solvent for the thiurams. The amount of test solution was always $5 \mu 1 ; 5 \mu 1$ of acetone was added to the control embryos.

The solutions were added to the air chamber according to the method described in principle by Bloom (1). After incubation for $3 \mathrm{~d}(72-76 \mathrm{~h})$ embryos of similar size were chosen from candled eggs. While the egg was in a vertical position, a hole of $4-6 \mathrm{~mm}$ in diameter was made in the wall of the air chamber with forceps. The embryo was readily seen under the inner shell membrane, which allowed the final selection of the embryos for the test. Abnormal embryos were discarded. With a Finnpipette the test solution was carefully dropped on the pulsating heart of the embryo. The hole was sealed with a piece of tape. After the addition of the test solution, the eggs were incubated in a vertical position for $1 \mathrm{~d}$. The temperature was kept at $37.8^{\circ} \mathrm{C}$, and the humidity between 66 and $71 \%$ throughout the incubation period. The

Table 1. Embryotoxic effects of tetramethylthiuramdisulfide (TMTD), tetramethylthiurammonosulfide (TMTM) and tetraethylthiuramdisulfide (TETD).

\begin{tabular}{|c|c|c|c|c|c|c|c|c|c|c|c|}
\hline \multirow{3}{*}{$\begin{array}{l}\text { Treatment } \\
\text { (nmol/egg) }\end{array}$} & \multirow{3}{*}{$\begin{array}{l}\text { Treated } \\
\text { embryos } \\
\text { (N) }\end{array}$} & \multirow{2}{*}{\multicolumn{2}{|c|}{$\begin{array}{c}\text { Early } \\
\text { deaths } \\
\text { (before } \\
\text { day 5) }\end{array}$}} & \multicolumn{4}{|c|}{ Late deaths (days $5-14$ ) } & \multirow{2}{*}{\multicolumn{2}{|c|}{$\begin{array}{l}\text { Malformed } \\
\text { survivors } \\
\text { (on day 14) }\end{array}$}} & \multirow{2}{*}{\multicolumn{2}{|c|}{$\begin{array}{l}\text { All affected } \\
\text { embryos }\end{array}$}} \\
\hline & & & & \multicolumn{2}{|c|}{$\begin{array}{c}\text { Non- } \\
\text { malformed } \\
\text { embryos }\end{array}$} & \multicolumn{2}{|c|}{$\begin{array}{l}\text { Malformed } \\
\text { embryos }\end{array}$} & & & & \\
\hline & & $\mathrm{N}$ & $\%$ & $N$ & $\%$ & $\mathrm{~N}$ & $\%$ & $\mathrm{~N}$ & $\%$ & $N$ & $\%$ \\
\hline \multicolumn{12}{|l|}{ TMTD } \\
\hline $\begin{array}{r}5 \\
10 \\
20 \\
40 \\
60 \\
80 \\
100\end{array}$ & $\begin{array}{r}42 \\
40 \\
50 \\
50 \\
50 \\
50 \\
50 \\
332\end{array}$ & $\begin{array}{r}5 \\
2 \\
7 \\
27 \\
35 \\
41 \\
44 \\
161\end{array}$ & $\begin{array}{r}12 \\
5 \\
14 \\
54 \\
70 \\
82 \\
88 \\
48\end{array}$ & $\begin{array}{r}0 \\
1 \\
2 \\
3 \\
4 \\
1 \\
0 \\
11\end{array}$ & $\begin{array}{l}0 \\
3 \\
4 \\
6 \\
8 \\
2 \\
0 \\
3\end{array}$ & $\begin{array}{r}0 \\
1 \\
2 \\
6 \\
5 \\
6 \\
5 \\
25\end{array}$ & $\begin{array}{r}0 \\
3 \\
4 \\
12 \\
10 \\
12 \\
10 \\
8\end{array}$ & $\begin{array}{r}1 \\
5 \\
18 \\
7 \\
3 \\
1 \\
0 \\
35\end{array}$ & $\begin{array}{r}2 \\
13 \\
36 \\
14 \\
6 \\
2 \\
0 \\
11\end{array}$ & $\begin{array}{r}6 \\
9 \\
29 \\
43 \\
47 \\
49 \\
49 \\
232\end{array}$ & $\begin{array}{l}14 \\
22 \\
58 \\
86 \\
94 \\
98 \\
98 \\
70\end{array}$ \\
\hline \multicolumn{12}{|l|}{ TMTM } \\
\hline $\begin{array}{r}15 \\
25 \\
40 \\
50 \\
100\end{array}$ & $\begin{array}{r}20 \\
40 \\
20 \\
30 \\
20 \\
130\end{array}$ & $\begin{array}{r}2 \\
9 \\
9 \\
15 \\
16 \\
51\end{array}$ & $\begin{array}{l}10 \\
23 \\
45 \\
50 \\
80 \\
39\end{array}$ & $\begin{array}{l}0 \\
1 \\
2 \\
1 \\
0 \\
4\end{array}$ & $\begin{array}{r}0 \\
3 \\
10 \\
3 \\
0 \\
3\end{array}$ & $\begin{array}{l}0 \\
2 \\
1 \\
1 \\
0 \\
4\end{array}$ & $\begin{array}{l}0 \\
5 \\
5 \\
3 \\
0 \\
3\end{array}$ & $\begin{array}{l}2 \\
1 \\
0 \\
3 \\
3 \\
9\end{array}$ & $\begin{array}{r}10 \\
3 \\
0 \\
10 \\
15 \\
7\end{array}$ & $\begin{array}{r}4 \\
13 \\
12 \\
20 \\
19 \\
68\end{array}$ & $\begin{array}{l}20 \\
32 \\
60 \\
67 \\
95 \\
52\end{array}$ \\
\hline \multicolumn{12}{|l|}{ TETD } \\
\hline $\begin{array}{r}40 \\
60 \\
80 \\
100 \\
120 \\
140 \\
160 \\
180 \\
200 \\
300\end{array}$ & $\begin{array}{r}30 \\
40 \\
30 \\
50 \\
40 \\
50 \\
52 \\
40 \\
40 \\
22 \\
394\end{array}$ & $\begin{array}{r}1 \\
5 \\
4 \\
9 \\
12 \\
27 \\
21 \\
23 \\
24 \\
17 \\
143\end{array}$ & $\begin{array}{r}3 \\
13 \\
13 \\
18 \\
30 \\
54 \\
40 \\
58 \\
60 \\
77 \\
36\end{array}$ & $\begin{array}{r}2 \\
0 \\
2 \\
2 \\
3 \\
2 \\
4 \\
2 \\
1 \\
1 \\
19\end{array}$ & $\begin{array}{l}7 \\
0 \\
7 \\
4 \\
8 \\
4 \\
8 \\
5 \\
3 \\
5 \\
5\end{array}$ & $\begin{array}{r}1 \\
1 \\
1 \\
7 \\
11 \\
7 \\
9 \\
5 \\
6 \\
2 \\
50\end{array}$ & $\begin{array}{r}3 \\
3 \\
3 \\
14 \\
28 \\
14 \\
17 \\
13 \\
15 \\
9 \\
13\end{array}$ & $\begin{array}{r}1 \\
4 \\
3 \\
10 \\
2 \\
4 \\
7 \\
1 \\
3 \\
0 \\
35\end{array}$ & $\begin{array}{r}3 \\
10 \\
10 \\
20 \\
5 \\
8 \\
13 \\
3 \\
8 \\
0 \\
9\end{array}$ & $\begin{array}{r}5 \\
10 \\
10 \\
28 \\
28 \\
40 \\
41 \\
31 \\
34 \\
20 \\
247\end{array}$ & $\begin{array}{l}17 \\
25 \\
33 \\
56 \\
70 \\
80 \\
79 \\
77 \\
85 \\
91 \\
63\end{array}$ \\
\hline Acetone, $5 \mu \mathrm{l}$ & 70 & 1 & 1 & 1 & 1 & 2 & 3 & 0 & 0 & 4 & 6 \\
\hline
\end{tabular}


eggs were turned two to four times per day.

Two days after the addition of the thiurams, after a total incubation period of $5 \mathrm{~d}$, the eggs were candled again. Eggs containing dead embryos were counted and discarded. The rest of the eggs were then candled every second or third day. Those containing dead embryos were opened and the embryos checked for external malformations and for the developmental stage as defined by Hamburger \& Hamilton (2). The incubation was terminated on day $14,11 \mathrm{~d}$ after the addition of the test solution. The remaining eggs were opened, and the embryos examined for survival and for external malformations.

The affected embryos were classified by the following categories of embryotoxicity: (i) early deaths - embryos dying before day 5 of incubation, within $2 \mathrm{~d}$ of treatment; (ii) late deaths, nonmalformed externally normal embryos dying between days 5 to 14; (iii) late deaths, malformed externally malformed embryos dying between days 5 to 14; (iv) malformed survivors - externally malformed embryos alive at day 14 of the incubation period. The median lethal dose $\left(\mathrm{LD}_{50}\right)$ and median effective dose $\left(E D_{50}\right)$ were calculated according to Rosiello et al (6) with a Wang table computer.

\section{Results}

The embryotoxicity of TMTD, TMTM, and TETD was studied in chick embryos. The numbers of embryos in each dose group and in each affected category are given in table 1. In table 1, as well as in all subsequent presentations of data, the percentages have been calculated per number of treated embryos. The acetone background, based on 70 embryos treated simultaneously with the thiuram series, is also shown in table 1 . The acetone background was $1.5 \%$ for the early deaths, $1.5 \%$ for the nonmalformed late deaths, and $3 \%$ for the malformed late deaths. No malformed survivors were found in the acetone series.

The dose-response curves for the data of table 1 are plotted on a probitlogarithmic scale in fig 1 . Three sets of graphs are formed, those for TMTD and TMTM falling in the low-dose region and that for TETD in the high-dose area.

Some quantitative parameters have been derived from the curves of fig 1 and presented in table 2. These include $\mathrm{ED}_{50}$ for embryotoxicity (total effect) and $\mathrm{LD}_{50}$ for total mortality, nonmalformed deaths, and early deaths scored on day 5. The slopes of the dose-response curves are also given. All of the calculated effective doses increase in the order TMTD $<$ TMTM $<$ TETD, the differences between TMTD and TETD being about fivefold. The slopes of the dose-response curves are similar, with the exception of that for total mortality. However, TMTM consistently appears to show the smallest values for the slopes of the dose-response curves.

The proportions of malformed embryos among those treated are shown in fig 2 . TMTD caused $40 \%$ malformations at a dose of $20 \mathrm{nmol} / \mathrm{egg}$ as compared to $34 \%$

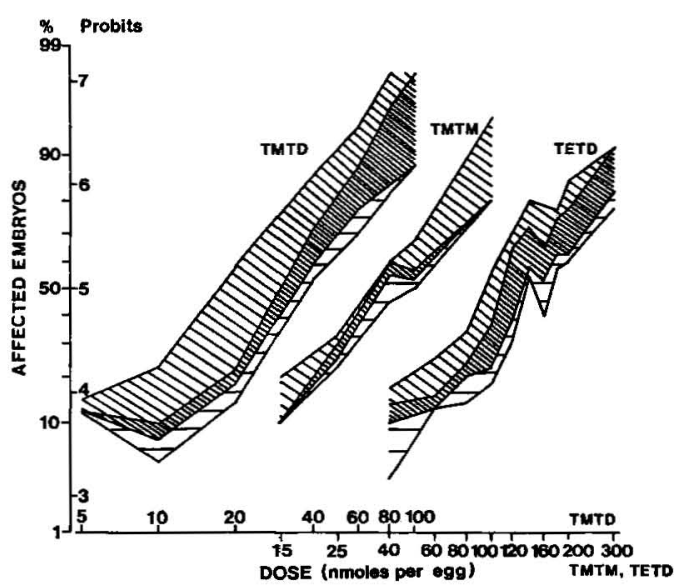

Fig 1. The teratogenic dose ranges of tetramethylthiuramdisulfide (TMTD) tetramethylthiurammonosulfide (TMTM), and tetraethylthiuramdisulfide (TETD). The dose scale is different for TMTD to avoid overlapping with TMTM. The effects on all the treated embryos are shown as percentage and on a probit scale (dose in a log scale). For each of the thiurams, the doseresponse curves show (from the right) early deaths, nonmalformed dead embryos (early deaths + nonmalformed late deaths), total mortality (early deaths + late deaths), and total effect (all affected embryos). The horizontally hatched area illustrates the category of nonmalformed late deaths; the area with heavy oblique hatching, the category of malformed late aeaths; and the area with light oblique hatching, the category of malformed survivors. 
Table 2. Median effective dose $\left(E D_{50}\right)$, median lethal dose ( $\left.L D_{50}\right)$, and the slope $(\tan \alpha)$ of the dose-response curves for the embryotoxic effects of tetramethylthiuramdisulfide (TMTD), tetramethylthiurammonosulfide (TMTM), and tetraethylthiuramdisulfide (TETD).

\begin{tabular}{|c|c|c|c|c|c|c|c|c|c|c|c|c|}
\hline & \multicolumn{3}{|c|}{ Total effect } & \multicolumn{3}{|c|}{ Total mortality } & \multicolumn{3}{|c|}{ Dead, not malformed } & \multicolumn{3}{|c|}{ Early deaths } \\
\hline & $\begin{array}{c}\mathrm{ED}_{50} \\
\text { (nmol/ } \\
\text { egg) }\end{array}$ & $\begin{array}{l}95 \% \\
\text { confi- } \\
\text { dence } \\
\text { limits } \\
\text { (nmol/ } \\
\text { egg) }\end{array}$ & $\tan a$ & $\begin{array}{l}\text { LD }_{50} \\
\text { (nmol/ } \\
\text { egg) }\end{array}$ & $\begin{array}{l}95 \% \\
\text { confi- } \\
\text { dence } \\
\text { limits } \\
\text { (nmol/ } \\
\text { egg) }\end{array}$ & $\tan \alpha$ & $\begin{array}{l}\text { LDso } \\
\text { (nmol/ } \\
\text { egg) }\end{array}$ & $\begin{array}{l}95 \% \\
\text { confi- } \\
\text { dence } \\
\text { limits } \\
\text { (nmol/ } \\
\text { egg) }\end{array}$ & $\tan \alpha$ & $\begin{array}{c}\mathrm{LD}_{50} \\
\text { (nmol/ } \\
\text { egg) }\end{array}$ & $\begin{array}{l}95 \% \\
\text { confi- } \\
\text { dence } \\
\text { limits } \\
\text { (nmol/ } \\
\text { egg) }\end{array}$ & $\tan a$ \\
\hline TMTD & 18 & $15-21$ & 1.3 & 28 & $25-32$ & 1.5 & 35 & $31-41$ & 1.2 & 40 & $35-46$ & 1.3 \\
\hline TMTM & 34 & $28-41$ & 1.3 & 39 & $32-48$ & 1.1 & 44 & $36-55$ & 1.1 & 48 & $38-60$ & 1.1 \\
\hline TETD & 91 & $81-100$ & 1.3 & 110 & $100-120$ & 1.4 & 150 & $130-170$ & 1.2 & 170 & $150-190$ & 1.3 \\
\hline
\end{tabular}

Table 3. Dose required to cause malformations in $10 \%$ of the treated embryos (ED 10 ) and the optimum teratogenic dose of tetramethylthiuramdisulfide (TMTD), tetramethylthiurammonosulfide (TMTM), and tetraethylthiuramdisulfide (TETD).

\begin{tabular}{lcccc}
\hline & & & Dose of TETD \\
\cline { 2 - 5 } & TMTD & TMTM & TETD & $\frac{\text { Dose of TMTD }}{\text { ED }}$ \\
\cline { 2 - 5 } Optimum teratogenic dose & 7.1 & 27 a & 46 & 6.5 \\
\hline
\end{tabular}

a The value of TMTM is arbitrary due to the shape of the dose-response curve (see fig 2).

Table 4. Incidence of different malformations produced by tetramethylthiuramdisulfide (TMTD), tetramethylthiurammonosulfide (TMTM), tetraethylthiuramdisulfide (TETD), and acetone.

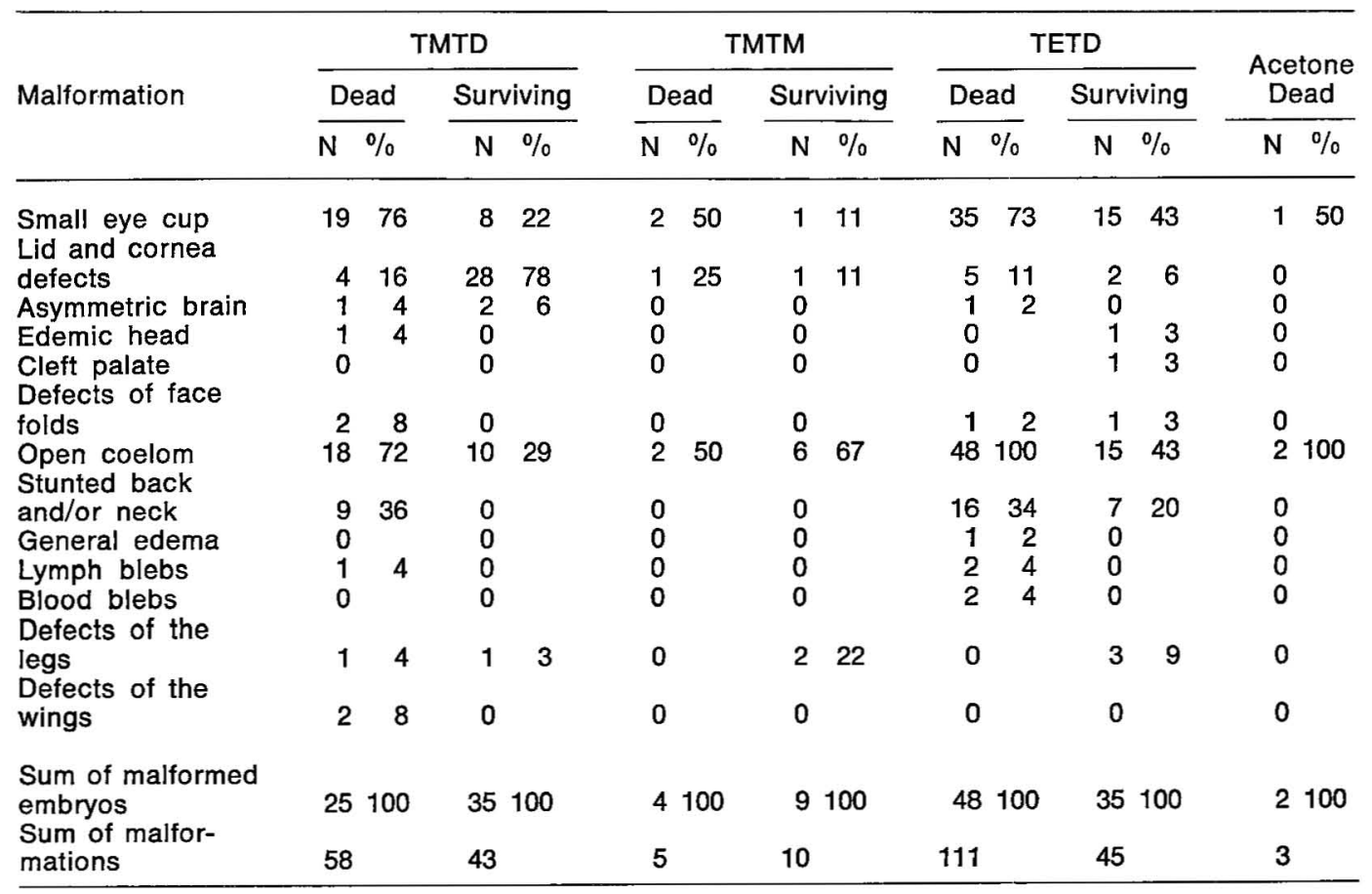


for TETD at a dose of $100 \mathrm{nmol} / \mathrm{egg}$. TMTM caused a rather low proportion of malformations at any of the tested concentrations; the highest percentage was 15 at $100 \mathrm{nmol} / \mathrm{egg}$. Fig 2 also shows the number of malformed embryos surviving at day 14. This number was quite high for TMTD, while for TETD about half of the malformed embryos were dead.

The data in fig 2 were used in the estimation of the dose required to cause malformations in $10 \%$ of the thiuramtreated embryos $\left(\mathrm{ED}_{10}\right)$ (table 3 ). The comparison suggested that TMTD was about three to five times more potent than TMTM and about six times more potent than TETD. The optimum teratogenic dose was $20 \mathrm{nmol} / \mathrm{egg}$ for TMTD and about $100 \mathrm{nmol} / \mathrm{egg}$ for the two other thiurams.

Embryos that died between days 5 and 14 were inspected for developmental stage and external malformations (fig 3 ). On the third day of incubation, the embryos had developed to stages 18 to 20 of the Hamburger-Hamilton scale (2). Two days later, when the embryos were examined for early death, the control embryos had developed to stage 26 . On day 14 , when the test was terminated, the control embryos had reached stages 38 and 39 . In all series, including the acetone series, scattered late deaths occurred between stages 27 and 37 . Most of the late deaths produced by TMTD and TETD occurred at stages $25 / 26$ and at stage 29 . In the TMTD series, $50 \%$ of the late deaths among the malformed and $67 \%$ of the late deaths among the nonmalformed embryos occurred around stage 26. With TETD, $60 \%$ of the malformed late deaths and $75 \%$ of the nonmalformed late deaths occurred around stage 29. The lack of dead embryos at stage 27 may be an artefact resulting from difficulties in distinguishing between stages 26,27 and 28 among the dead, often very small and severely malformed, embryos.

An important observation from fig 3 is that most of the embryos that died late were malformed. In the TMTD series $70 \%$ and in the TETD series $73 \%$ of the dead embryos had external malformations.

The major types of malformations were similar in all the groups studied (table 4). Specific anomalies included two kinds of eye defects, defects of the coelomic wall,

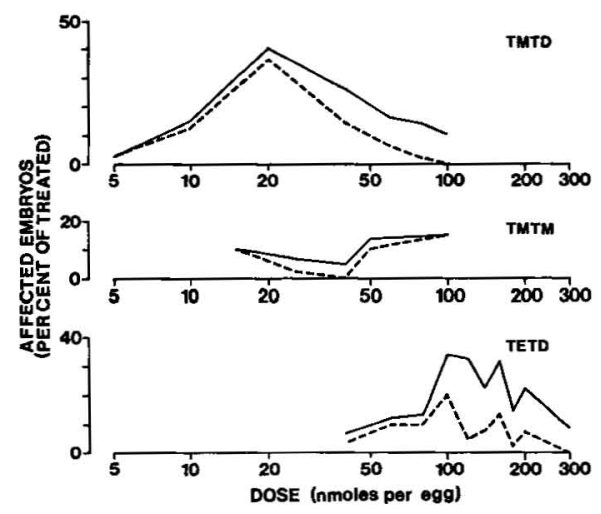

Fig 2. Percentage of malformed embryos $(-)$ and malformed survivors (-- - ) among the treated. (TMTD = tetramethylthiuramdisulfide, TMTM = tetramethylthiurammonosulfide, TETD = tetraethylthiuramdisulfide)

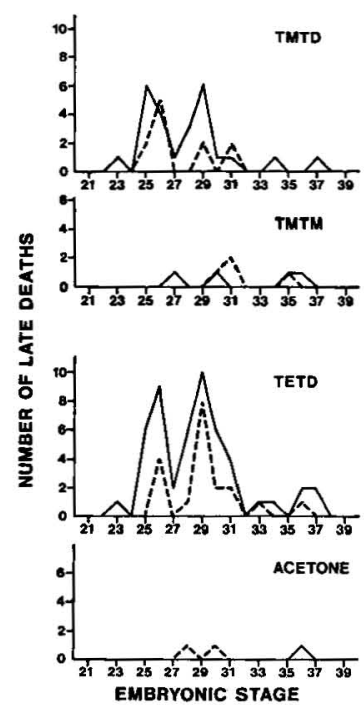

Fig 3. Occurrence of late deaths (malformed -, nonmalformed -.--) at different embryonic stages of the Hamburger-Hamilton scale. (TMTD = tetramethylthiuramdisulfide, TMTM = tetramethylthiurammonosulfide, $\quad$ TETD $=$ tetraethylthiuramdisulfide)

and deformation of the dorsal side of the body.

One type of eye defect involved the eye cup, which varied from total absence to near normal size. The sizes of the cornea, lens and lids were proportional to the size of the eye cup. The other eye defect type was a partial or total absence of the lids and the cornea. This defect extended occasionally to the head region behind the 
eye, with the brain bulging from an opening in the skin and the skull. In mild cases, only the skin on the head was affected. The eye cup defect was unilateral in the right eye in 35 cases and in the left eye in 9 cases of a total of 81, covering all the treated groups. In the remaining 36 cases it occurred in both eyes, while there was a preponderance of more severe defects in the right eye. The superficial defect was always unilateral, occurring in the right eye in 39 cases and in the left eye in 2 cases.

The coelomic wall defect varied from umbilical hernias and wide open umbilical stalks to total exteriorization of the viscera. The dorsal defect included twisting, bending, and shortening of the back and neck. The whole dorsal half of the embryo could be small in comparison to the belly.

One difference between the dead and the surviving embryos appeared to stand out irrespective of which thiuram was used. Dead embryos frequently exhibited multiple malformations, while the surviving ones usually had only a single malformation (table 4). An additional feature was that dead embryos of the TMTD and TETD series frequently showed small eye cups and open coeloms.

\section{Discussion}

The chicken has been extensively used to assess the embryotoxicity of chemicals (7). Although opinions have been divided on the usefulness of the chicken embryo in predicting teratogenicity (9), more recently the system has been increasingly appreciated for reasons such as inexpensiveness, sensitivity, and parallelism to mammalian morphological development (8). A central problem in teratology is the species specificity of a teratogenic effect. Death of the dam may mask the effect of a teratogen on the embryo of one species, rendering the tested agent nonteratogenic. Another species may be more resistant to lethal effects, and malformed embryos may be detected at similar doses. In the chicken embryo test the chemicals affect the embryo directly, and both deaths and malformations may be monitored. As there is no single species that could be used reliably as a model for human teratogenesis, every toxic chemical must be tested on several species. The chicken embryo method is a practical and rapid way to make a basic catalog of the comparative toxicity of different agents to one kind of the amniotic embryo (3). Comparing this catalog to others obtained with different mammalian species is helpful in predicting teratogenic potential. In the present communication we wish to emphasize yet another valuable asset of the avian system, that of continuous observation of the developing embryo. This possibility facilitates the distinction of the various embryotoxic parameters. The time of death may be determined, and the dead embryos may be inspected for malformations before maceration. Thus the following embryotoxic effects may be recorded: early deaths (embryos dying within $2 \mathrm{~d}$ of treatment), late deaths divided into malformed and nonmalformed embryos, and malformed survivors (table $1 \&$ fig 1 ).

The embryotoxic parameters were developed with three thiuram compounds. It was notable that the calculated parameters, $\mathrm{ED}_{50}$ and $\mathrm{LD}_{50}$ for early deaths, nonmalformed deaths, total mortality, and total effect (table 2), varied uniformly between the various thiurams. TMTD had the lowest values, being the most potent embryotoxic agent; TMTM was intermediate; and TETD was the least embryotoxic agent. The dose-response curves of the thiurams for the parameters mentioned had fairly similar slopes.

The efficiency of the different thiurams to cause malformations correlated with their general embryotoxic potency. The $\mathrm{ED}_{10}$ for malformations was $7.1 \mathrm{nmol} / \mathrm{egg}$ for TMTD, $27 \mathrm{nmol} / \mathrm{egg}$ for TMTM, and $46 \mathrm{nmol} / \mathrm{egg}$ for TETD. In a mammalian study TIMTD has been shown to be more potent than TETD, which has been active only when administered in dimethylsulfoxide (4).

The present results showed that most (about $70 \%$ ) of the embryos that died between days 5 to 14 were externally malformed. Among dead embryos small eyes and open coeloms were the prevailing types of malformations, while in the surviving embryos a more even distribution of various types of malformations was 
observed. Dead embryos frequently exhibited multiple malformations. There were, on the average, more than two external malformations per embryo in the dead series as compared to only slightly more than one per embryo in the surviving series. This result may indicate that malformations in some vital organs may be related to the mortality of the embryo. Most of the deaths occurred at embryonic stages $25 / 26$ and 29, when, among other embryonic events, the allantoic system rapidly develops to reach the shell membrane.

In the present article we have described the parameters of embryotoxicity that can be derived from the continuous observation of developing avian embryos. Three thiurams were used as model compounds. In subsequent studies more industrial chemicals will be assayed in order to establish relative orders of embryotoxicity among important groups of industrial chemicals.

\section{Acknowledgments}

The project has been supported by the Swedish Work Environment Fund.

\section{References}

1. Bloom SE. Chick embryos for detecting environmental mutagens. In: Hollaender A, de Serres FJ, ed. Chemical mutagenesis: Principles and methods for their detection. Volume 5. Plenum Press, New York, NY 1978, pp 203-231.

2. Hamburger V, Hamilton HL. A series of normal stages in the development of the chick embryo. J morphol 88 (1951) 49-92.

3. Jelinek R, Rychter Z. Morphogenetic systems and the central phenomena of teratology. In: Persaud TVN, ed. Advances in the study of birth defects: Teratological testing. Volume 2. MTP Press Ltd, Lancaster (England) 1979 , pp $41-67$.

4. Robens JF. Teratologic studies of carbaryl, diazinon, norea, disulfiram and thiram in small laboratory animals. Toxicol appl pharmacol 15 (1969) 152--163.

5. Roll R. Teratologische Untersuchungen mit Thiram (TMTD) an zwei Mäusestämmen. Arch toxicol 27 (1971) 173-186.

6. Rosiello AP, Essigmann JM, Wogan GN. Rapid and accurate determination of the median lethal dose (LD 50) and its error with a small computer. $J$ toxicol environ health 3 (1977) 797-809.

7. Shepard TH. Catalog of teratogenic agents. Johns Hopkins University Press, Baltimore, MD 1976.

8. Wilson JG. Environmental chemicals. In: Wilson JG, Fraser FC, ed. Handbook of teratology. Volume 1. Plenum Press, New York NY 1977, pp 357-385.

9. World Health Organization Scientific Group. Principles for the testing of drugs for teratogenicity. World Health Organization, Geneva 1967. (Technical report series no 364 ). 